\title{
Navigated transcranial magnetic stimulation in preoperative planning for the treatment of motor area cavernous angiomas
}

This article was published in the following Dove Press journal:

Neuropsychiatric Disease and Treatment

6 December 2013

Number of times this article has been viewed

\author{
Wellingson Silva Paiva' \\ Erich Talamoni Fonoff' \\ Marco Antonio Marcolin ${ }^{2}$ \\ Edson Bor-Seng-Shu' \\ Eberval Gadelha Figueiredo' \\ Manoel Jacobsen Teixeira' \\ 'Division of Neurosurgery, \\ Department of Neurology, School \\ of Medicine, University of Sao Paulo, \\ Sao Paulo, Brazil; ${ }^{2}$ Transcranial \\ Magnetic Stimulation Laboratory, \\ Institute of Psychiatry, School of \\ Medicine, University of Sao Paulo, \\ Sao Paulo, Brazil
}

\begin{abstract}
Since the introduction of microscopic techniques, radical surgery for cavernous angiomas has become a recommended treatment option. However, the treatment of motor area cavernous angioma represents a great challenge for the surgical team. Here, we describe an approach guided by frameless neuronavigation and preoperative functional mapping with transcranial magnetic stimulation (TMS), for surgical planning. We used TMS to map the motor cortex and its relationship with the angioma. We achieved complete resection of the lesions in the surgeries, while avoiding areas of motor response identified during the preoperative mapping. We verified the complete control of seizures (Engel class 1A) in the patients with previous refractory epilepsy. Postsurgery, one patient was seizure-free without medication, and two patients required only one medication for seizure control. Thus, navigated TMS appears to be a useful tool, in preoperative planning for cavernous angiomas of the motor area.
\end{abstract}

Keywords: neurosurgical procedures, brain mapping, neuronavigation

\section{Introduction}

Localization of the primary motor cortex is an important neurosurgical consideration when treating lesions in the motor area. ${ }^{1} \mathrm{~A}$ major problem in the preoperative planning of surgery for central lesions is the exact assessment of the spatial relationship between pathology, function, and anatomy. ${ }^{2}$ The symptoms of cavernous angiomas include epileptic seizures, headaches, and focal neurological deficits. Patients with symptomatic angiomas can be treated either conservatively, or with resection, if lesions cause medically refractory epilepsy. ${ }^{3}$ Since the introduction of microscopic techniques, radical surgery for cavernous angiomas has become a recommended treatment option. ${ }^{4}$ However, the treatment of motor area cavernous angioma represents a great challenge for the surgical team. Intraoperative mapping of the motor cortex to direct electrical cortical stimulation (DES) remains the gold standard in the resection of lesions in the motor area. ${ }^{5}$ However, this technique only allows determination of the motor area during the surgery and in addition, requires a large craniotomy for cortical exposure. For the precise localization of the motor cortex and its relations with the brain lesion, navigated transcranial magnetic stimulation (TMS) has been tested to map the motor cortex preoperatively. ${ }^{6-8}$ This method releases magnetic impulses, inducing an electric field on the cortical surface, similar to intraoperative DES. ${ }^{6}$ However, there are no studies of the use of TMS to guide the surgical approach for angiomas. In the present report, we describe the use of a frameless neuronavigation-guided approach and preoperative functional mapping by TMS to plan the surgical approach in motor cortex cavernous angiomas.
Correspondence: Wellingson Silva Paiva University of Sao Paulo Medical School, 225 Eneas Aguiar, Street number 255 Office 4080, Sao Paulo, 054030 I0, Brazi Tel +55 II 266 | 7226

Fax +55 II 25486906

Email wellingsonpaiva@yahoo.com.br 


\section{Methods}

A prospective study was performed in three patients with the diagnosis of motor area cavernous angioma, two men and a woman. The mean age of the patients was 47 years (Table 1). We decided to perform preoperative planning with navigated TMS to map the motor cortex and define the best surgical approach. This study was approved by our institutional ethics committee (Ethics Committee for Analysis of Research Projects of the University of Sao Paulo; study number 0393/08). Our patients underwent magnetic resonance imaging (MRI) using a $1.5 \mathrm{~T}$ Magnetom Vision scanner (Siemens AG, Erlangen, Germany). A neuronavigation device (BrainSight 2, Rogue Research Inc, Montréal, QC, Canada) sensor was applied to guide the coil positioning, which allowed visualization of the angle of impact for the magnetic impulse onto the brain surface. Subsequently, a system was introduced that also facilitated elucidation of the exact strength and extent of the induced electrical field, depending on the depth of the area under the coil. The MRI images were recorded in digital imaging and communications in medicine (DICOM), with sections of $1.0 \mathrm{~mm}$ thickness and spatial resolution $1.0 \mathrm{~mm} \times 1.0 \mathrm{~mm} \times 1.0 \mathrm{~mm}, 120$ axial slices. However, we also conducted a mapping with DES, for intraoperative assessment of the motor area and for comparison with the TMS mapping as a secondary objective. In addition to the structure-function correlation of TMS, this technique further allowed for the integration of different brain mapping methodologies, by providing a common coordinate system for the DES maps. Motor activity was analyzed with surface electrodes, which measured the activity of the hand muscles. We performed navigated TMS mapping one day before the surgery, and we used this mapping to plan the surgical approach.

For the TMS mapping, the patients were seated on a chair with a headrest. Focal single-pulse TMS was delivered to the motor cortex with a figure-of-eight magnetic stimulator (diameter $70 \mathrm{~mm}$; 9 turns of the wire; peak magnetic $-2.2 \mathrm{~T}$ ) (MagPro $\times 100 ;$ MagVenture A/S, Farum, Denmark). The magnetic coil was placed with navigation. We performed a coregistration of MRI for face recognition by points (glabella, nasium, right tragus, and left tragus). The motor cortex was identified, using TMS impulses in the cortex to produce movement in the contralateral hand. The motor threshold was considered as the lowest intensity of TMS required to induce a motor-evoked potential with an amplitude $50 \mathrm{mV} \geq 50 \%$ of the stimuli, in five of ten consecutive stimuli. A stimulation intensity of $120 \%$ of the motor threshold was used to map the motor area. For navigation, the BrainSight software system was used, for the visualization of the coil location in relation to the cortex. After coregistration, the image of the patient's brain was represented in a coordinate system (defining coordinate $\mathrm{X}, \mathrm{Y}$, and $\mathrm{Z}$ ), such that the position of the coil with respect to the brain could be visualized on the corresponding three dimensional (3D) MR image shown by the navigation system (Figure 1B). After the TMS mapping, we evaluated the results, and before surgery, we decided on the best approach for each patient.

In the surgeries, the transsulcal approach (in the medial region of the central sulcus) (Figure 1B) was successfully applied to the lesions, and the areas of motor response identified by the preoperative mapping were carefully avoided. In the surgeries, we also used DES, which confirmed the cortical areas with motor response that were identified with TMS. The DES at the time of surgery was performed with a handheld constant-current bipolar stimulator (Micromar, Diadema, Brazil) at $50 \mathrm{~Hz}$, using a biphasic square wave and a pulse width of $1.0 \mathrm{~ms}$. For comparison of the mapping methods, we calculated the distance of mean vectors in each patient.

\section{Results}

Three patients were operated on using this method. Before the surgeries, two patients had refractory epilepsy, and one patient with previous epilepsy, was admitted in our emergency room with a frontal hematoma. None of the patients had a motor deficit at the time of the TMS mapping.

Table I Distribution of patients according to clinical characteristics

\begin{tabular}{|c|c|c|c|c|c|c|c|c|}
\hline & $\begin{array}{l}\text { Age } \\
\text { (years) }\end{array}$ & Sex & $\begin{array}{l}\text { Size } \\
(\mathrm{mm})\end{array}$ & Side & Symptom & $\begin{array}{l}\text { Duration of } \\
\text { epilepsy (years) }\end{array}$ & $\begin{array}{l}\text { Follow-up } \\
\text { (months) }\end{array}$ & Outcome at follow-up \\
\hline Patient I & 47 & M & 27 & Left & $\begin{array}{l}\text { Simple partial seizure } \\
\text { Headache }\end{array}$ & 7 & 28 & $\begin{array}{l}\text { Seizure control with medication } \\
\text { No deficits }\end{array}$ \\
\hline Patient 2 & 42 & $\mathrm{~F}$ & 33 & Left & Simple partial seizure & 14 & 24 & $\begin{array}{l}\text { Seizure control with medication } \\
\text { No deficits }\end{array}$ \\
\hline Patient 3 & 54 & $\mathrm{~F}$ & 25 & Right & Simple partial seizure & 23 & 25 & $\begin{array}{l}\text { No seizures } \\
\text { No deficits }\end{array}$ \\
\hline
\end{tabular}

Abbreviations: $F$, female; $M$, male. 


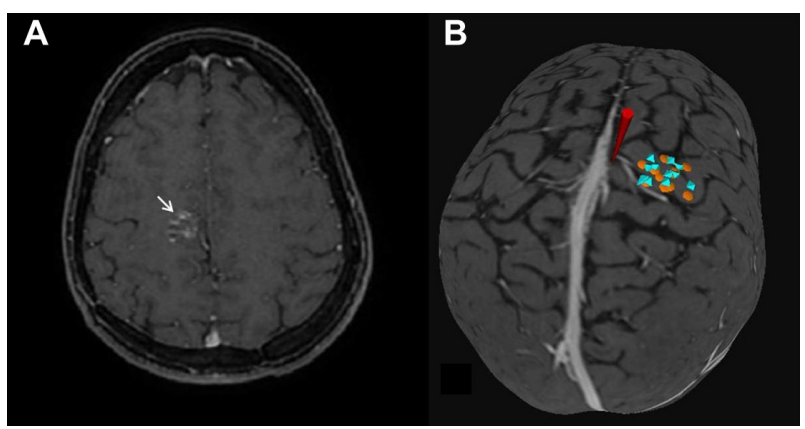

Figure I (A) Axial magnetic resonance image showing a cavernous hemangioma in the precentral gyrus. (B) Three-dimensional brain image.

Notes: In (B), the yellow circle represents cortical electric stimulation mapping The blue octahedron represents the point of TMS mapping. The red cone represents the planned point of transsulcal approach, in the central sulcus behind the vein, an appropriate distance from motor area mapped by TMS and confirmed by DES.

Abbreviations: DES, direct cortical electrical stimulation; TMS, transcranial magnetic stimulation.

We performed small craniotomies, with a maximum diameter of $4 \mathrm{~cm}$, considering the plan already defined with TMS mapping. We had identified the motor cortex of the hand (M1), upper limb, and face. We planned the surgical approach to the central sulcus, angling anteriorly in the white matter of the precentral gyrus (the region without motor response in the TMS response). We found no intraoperative seizures or infections in our patients. A complete excision of the cavernous angioma was achieved in these patients. One of three patients had worsening, but recovered after 2 months with physical therapy. We verified the complete control of seizures (Engel class $1 \mathrm{~A}^{3}$ ) in the patients with previous refractory epilepsy (with a minimum follow-up period of 24 months). One patient was seizure-free without medication, and two patients required only one medication for seizure control.

Both the TMS mapping and the DES mapping were performed without difficulty. The cortical mapping with DES was performed for intraoperative confirmation and was congruent with TMS mapping in all patients. The accuracy of both methods for cortical mapping was high. The distance between the hotspots of the mapping was $3.8 \mathrm{~mm}$ in patient 1 , 4.4 in patient 2 , and $5.7 \mathrm{~mm}$ in patient 3 , with an average distance of $4.7 \mathrm{~mm}$ (Table 2).

\section{Illustrative case}

A 54-year-old woman presented with refractory epilepsy with complex partial seizures. She displayed motor components in the left hand, without motor deficits. The patient underwent MRI, which revealed a cavernous angioma lesion - approximately $25 \mathrm{~mm}$ in diameter - occupying the precentral gyrus subcortical region (Figure 1A). After an
Table 2 Mapping studies with TMS and accuracy compared with DES

\begin{tabular}{llll}
\hline Study & N & $\begin{array}{l}\text { Accuracy of } \\
\text { TMS/DES }\end{array}$ & Histology \\
\hline${\text { Picht et } \mathrm{al}^{7}}$ & 10 & $6.6 \mathrm{~mm}$ & Tumor \\
${\text { Kantelhardt et } \mathrm{al}^{10}}$ & 02 & $16.9 \mathrm{~mm}$ & Tumor \\
${\text { Picht et } \mathrm{al}^{9}}$ & 20 & $7.83 \mathrm{~mm}$ & Tumor \\
Forster et al $^{8}$ & 17 & $10.5 \mathrm{~mm}$ & Tumor \\
${\text { Paiva et } \mathrm{al}^{\prime \prime}}^{\text {Paiva et al* }}$ & 06 & $4.16 \mathrm{~mm}$ & Tumor (low-grade glioma) \\
\hline
\end{tabular}

Note: *Average mapping distance in three patients in the present study. Abbreviations: DES, direct cortical electrical stimulation; TMS, transcranial magnetic stimulation.

unsuccessful attempt at treating the lesion medically, the patient was referred for surgical treatment. The location of M1 was detected preoperatively.

A complete excision of the cavernous angioma was achieved in this patient. However, worsening of the motor deficit was observed in the immediate postoperative period in the patient. Therefore, the patient underwent physical therapy, with 4 weekly sessions and guided physical activity at home. The patient had grade III muscle strength in the immediate postoperative period, and the motor deficit was primarily observed in the left lower limb. However, after 2 months of physical therapy, the patient showed complete recovery of motor deficit. Furthermore, the patient was seizure-free after resection of the cavernous angioma.

\section{Discussion}

Epileptic seizures are the most frequent symptom of patients with cavernous angiomas. Some studies have confirmed that the complete removal, not only of the cavernous angioma itself but also, of the surrounding hemosiderin-stained brain tissue, improves the long-term outcome of seizures in symptomatic epilepsy. ${ }^{1,4}$ However, considering the risk/benefit of procedures in the motor area, we did not remove the hemosiderin-stained tissue in two of our patients.

The interhemispheric approach was not possible in our patients due to the multitude of veins that run between the dura and the surface of the brain (bridging veins) in the region of the cavernoma. Therefore, a transsulcal approach was the only viable option for treatment of these patients. Cavernous angiomas of the motor area represent a major challenge for a surgical team. The goal is to resect the lesion to provide seizure control. Proper planning prior to surgery can result in functional preservation. Furthermore, intraoperative DES is the gold standard for functional mapping of the primary motor cortex. However, if intraoperative complications are 
encountered, these can lead to abandonment of DES mapping altogether. Moreover, it is not possible to obtain preoperative information with DES. ${ }^{7}$

The clinical utility of TMS mapping in brain tumor surgery has recently been evaluated..$^{2,4,8-11}$ Picht et $\mathrm{al}^{7}$ and Forster et $\mathrm{al}^{8}$ have mapped the motor cortex in patients suffering from growing malignant and large tumors. The distances from TMS to DES in these studies were $7.83 \mathrm{~mm}$ and $10.5 \mathrm{~mm}$, respectively. These reports described mapping protocols that were noninvasive and free of any known risks. In our patients, we verified the mean distance of $4.7 \mathrm{~mm}$ between the two maps. This was likely aided by the small size of the lesions and absence of surrounding edema, which would allow for greater accuracy. In a previous other investigation, in a sample of patients without major anatomical deformity of the precentral gyrus, ${ }^{11}$ we reported a distance from TMS to DES of approximately $4 \mathrm{~mm}$. The major advantage of TMS is that it is conducted preoperatively. The use of a preoperative planning approach in this patient facilitated the identification of the region of the precentral gyrus that showed no motor response, and thus guided the surgeon to the point of greater safety to reach the cavernoma. Through this mapping, it was possible to accurately define the motor areas.

\section{Conclusion}

This is the first report describing the use of TMS for mapping and surgical planning in patients with cavernous angioma. This method appears to be a useful tool in the preoperative planning of the surgical approach in cavernous angiomas of the motor area.

\section{Disclosure}

The authors report no conflicts of interest in this work.

\section{References}

1. Möller-Hartmann W, Krings T, Coenen VA, et al. Preoperative assessment of motor cortex and pyramidal tracts in central cavernoma employing functional and diffusion-weighted magnetic resonance imaging. Surg Neurol. 2002;58(5):302-307; discussion 308.

2. Sakurada K, Kayama T, Sato S, et al. Motor area cavernous angioma: case report. Surg Neurol. 2000;53(4):337-339.

3. Hugelshofer M, Acciarri N, Sure U, et al. Effective surgical treatment of cerebral cavernous malformations: a multicenter study of 79 pediatric patients. J Neurosurg Pediatr. 2011;8(5):522-525.

4. Zhou H, Miller D, Schulte DM, et al. Transsulcal approach supported by navigation-guided neurophysiological monitoring for resection of paracentral cavernomas. Clin Neurol Neurosurg. 2009;111(1):69-78.

5. Penfield W, Jasper HH. Epilepsy and the Functional Anatomy of the Human Brain. Boston, MA: Little, Brown and Co; 1954.

6. Coburger J, Musahl C, Henkes H, et al. Comparison of navigated transcranial magnetic stimulation and functional magnetic resonance imaging for preoperative mapping in rolandic tumor surgery. Neurosurg Rev. 2013;36(1):65-75; discussion 75-76.

7. Picht T, Schmidt S, Brandt S, et al. Preoperative functional mapping for rolandic brain tumor surgery: comparison of navigated transcranial magnetic stimulation to direct cortical stimulation. Neurosurgery. 2011;69(3):581-588; discussion 588.

8. Forster MT, Hattingen E, Senft C, Gasser T, Seifert V, Szelényi A. Navigated transcranial magnetic stimulation and functional magnetic resonance imaging: advanced adjuncts in preoperative planning for central region tumors. Neurosurgery. 2011;68(5):1317-1324; discussion 1324-1325.

9. Picht T, Mularski S, Kuehn B, Vajkoczy P, Kombos T, Suess O. Navigated transcranial magnetic stimulation for preoperative functional diagnostics in brain tumor surgery. Neurosurgery. 2009; 65(Suppl 6):S93-S98; discussion 98-99.

10. Kantelhardt SR, Fadini T, Finke M, et al. Robot-assisted image-guided transcranial magnetic stimulation for somatotopic mapping of the motor cortex: a clinical pilot study. Acta Neurochir (Wien). 2010;152(2): 333-343.

11. Paiva WS, Fonoff ET, Marcolin MA, Cabrera HN, Teixeira MJ. Cortical mapping with navigated transcranial magnetic stimulation in low-grade glioma surgery. Neuropsychiatr Dis Treat. 2012;8:197-201.
Neuropsychiatric Disease and Treatment

\section{Publish your work in this journal}

Neuropsychiatric Disease and Treatment is an international, peerreviewed journal of clinical therapeutics and pharmacology focusing on concise rapid reporting of clinical or pre-clinical studies on a range of neuropsychiatric and neurological disorders. This journal is indexed on PubMed Central, the 'PsycINFO' database and CAS.

\section{Dovepress}

The manuscript management system is completely online and includes a very quick and fair peer-review system, which is all easy to use. Visit http://www.dovepress.com/testimonials.php to read real quotes from published authors. 